Implantologie

\section{Optimale Barriere statt überflüssige Blockade}

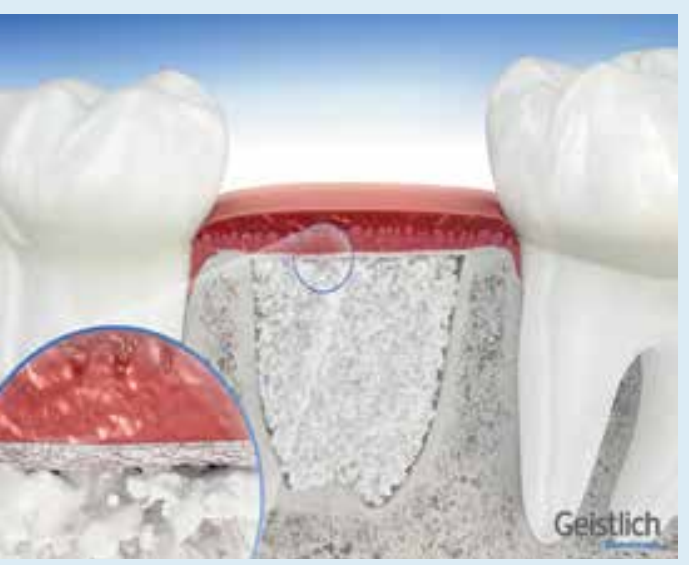

Führende Implantologen sind sich einig: Die Barrierefunktion ist nur für wenige Wochen bis zur Ausbildung der provisorischen Knochenmatrix nötig (Bericht vom 2. Internationalen Scientific Expert Meeting zum Thema Membranen, 2011 Luzern, $\mathrm{CH}$ ). Geistlich Bio-Gide ist mehr als nur eine Barriere. Ihre hydrophile Eigenschaft erlaubt nicht nur ein einfaches Handling, sondern sorgt auch für eine starke Adhäsion am Defekt. Dies stabilisiert das Augmentat und verhindert den Verlust von partikulärem Material. Gleichzeitig bietet sie eine hervorragende Leit- schiene für die Wundheilung und unterstützt die Knochenneubildung. Selbst im seltenen Fall einer Nahtdehiszenz zeigt die klinische Erfahrung in der Regel eine Wundheilung ohne Infektion und ohne Gefahr für das Augmentat. Das Produkt trägt damit entscheidend zur Therapiesicherheit bei. Geistlich Bio-Gide wird seit 18 Jahren erfolgreich in Kombination mit Geistlich Bio-Oss zur Regeneration von Hart- und Weichgewebe verwendet und ist für die Mehrzahl der Implantologen und Parodontologen die Membran der Wahl.

Nach einer Pressemitteilung der Geistlich Biomaterials Vertriebsgesellschaft mbH, Baden-Baden

Internet: www.geistlich.de 